\title{
FLOW AND BED SHEAR MAGNIFICATION DOWNSTREAM OF A BARRAGE WITH SWIRL GENERATED IN DUCTS BY STATORS AND ROTORS
}

DOI:

10.1061/(ASCE)HY.1943-7900.0001228\#sthash.XC9XDUKy.dpuf

\section{Document Version}

Accepted author manuscript

Link to publication record in Manchester Research Explorer

Citation for published version (APA):

Jeffcoate, P., Stansby, P., \& Apsley, D. (2016). FLOW AND BED SHEAR MAGNIFICATION DOWNSTREAM OF A BARRAGE WITH SWIRL GENERATED IN DUCTS BY STATORS AND ROTORS. Journal of Hydraulic

Engineering. https://doi.org/10.1061/(ASCE)HY.1943-7900.0001228\#sthash.XC9XDUKy.dpuf

Published in:

Journal of Hydraulic Engineering

\section{Citing this paper}

Please note that where the full-text provided on Manchester Research Explorer is the Author Accepted Manuscript or Proof version this may differ from the final Published version. If citing, it is advised that you check and use the publisher's definitive version.

\section{General rights}

Copyright and moral rights for the publications made accessible in the Research Explorer are retained by the authors and/or other copyright owners and it is a condition of accessing publications that users recognise and abide by the legal requirements associated with these rights.

\section{Takedown policy}

If you believe that this document breaches copyright please refer to the University of Manchester's Takedown Procedures [http://man.ac.uk/04Y6Bo] or contact uml.scholarlycommunications@manchester.ac.uk providing relevant details, so we can investigate your claim.

\section{OPEN ACCESS}




\title{
FLOW AND BED SHEAR MAGNIFICATION DOWNSTREAM OF A BARRAGE WITH
}

\section{SWIRL GENERATED IN DUCTS BY STATORS AND ROTORS}

\author{
Penny Jeffcoate ${ }^{1}$, Peter Stansby ${ }^{2}$, David Apsley ${ }^{3}$
}

\section{ABSTRACT}

In this paper the flow and bed shear stresses downstream of a tidal barrage, with open ducts and with swirl created by stators and rotors, are investigated experimentally. The wake created by open ducts is significantly three-dimensional within 20 duct diameters $(20 D)$ from the barrage. Here, within $20 D$ of the barrage the duct blockage and swirl also affect flow patterns and bed shear stress. Swirl affects jet mixing and local downstream circulation within $5 D$, resulting in large-scale cross-stream circulation further downstream. After $20 D$ the flow becomes predominantly parallel and depth-averaging would be appropriate. Bed shear stress just downstream of the barrage is magnified by up to 3, 7 and 12 times respectively for open ducts, stators alone and rotors plus stators. This has major implications for sediment motion and scour. Keywords: Tidal Power, Jets (fluid), Ducts, Open Channel Flow, Turbine Wake

\section{INTRODUCTION}

Previous tidal barrage studies have been conducted to determine the impacts of tidal barrages on the environment, to provide better understanding for potential future barrage installation (Burrows et al 2009, Xia et al 2010, Ahmadian et al 2010). Recently, three-dimensional flows in the near-field of a barrage without turbines (with open ducts) have been investigated by Jeffcoate (2013) and Jeffcoate et al (2013). Three-dimensional flows due to turbine wakes have been

\footnotetext{
${ }^{1}$ Dr. Penny Jeffcoate, Sustainable Marine Energy. penny.jeffcoate@sustainablemarine.com, Trinity Wharf, East Cowes, Isle of Wight, UK, PO32 6RF

${ }^{2}$ Prof. Peter Stansby, University of Manchester. p.k.stansby@manchester.ac.uk, Pariser Building, School of Mechanical, Aerospace and Civil Engineering, University of Manchester, UK, M13 9PL

${ }^{3}$ Dr. David Apsley, University of Manchester. d.apsley@manchester.ac.uk, Pariser Building, School of Mechanical, Aerospace and Civil Engineering, University of Manchester, UK, M13 9PL
} 
studied extensively for tidal stream turbines in both experimental (Stallard et al 2013, Myers et al 2011, Luznik et al 2013) and computational studies (Harrison et al 2010, McNaughton et al 2014). The wake in these studies is found to be rotational in the near field, determining turbine performance, and extends at least two diameters downstream from the turbine. Unbounded and ducted turbines have been investigated, but similar experiments have not been conducted for turbines within a barrage.

Depth-averaging these near-field flows may limit the accuracy of flow predictions due to the rotational, and highly three-dimensional (3-d), nature of the barrage wake. For open ducts, experimental and computational models of the near-field, 3-d flow were conducted in Jeffcoate et al (2013), showing good agreement between experimental velocity measurements and standard computational fluid dynamics (CFD); the results also showed that bed shear was considerably magnified above that for channel flow with corresponding average velocity in the water column. 3-d analysis was required within $20 D$ ( $D$ is duct diameter) of the barrage due to large vertical velocity variation in the flow, but depth-averaged modelling could be used further downstream (though this may be dependent on the flow and set-up conditions tested). Analysis of the flow with turbines included is also of great concern.

In this paper the flow and bed shear stress resulting from seven equi-spaced jets from a barrage with turbine representation is investigated. The turbines are idealised in laboratory experiments: firstly, with bulb bodies with stators only providing swirl, and then with rotors included.

\section{EXPERIMENTAL METHODOLOGY}

A 1:143 scale model (based on Department of Energy Paper 1981) with seven draft tubes of constant radius, $R=0.055 \mathrm{~m}$, was placed in a flume. The barrage dimensions were $0.539 \mathrm{~m}$ long $\times$ 
$1.22 \mathrm{~m}$ wide $\times 0.28 \mathrm{~m}$ high with flow regions of $1.1 \mathrm{~m}$ upstream and $2.8 \mathrm{~m}$ downstream of the barrage. A three-component Vectrino ADV (Acoustic Doppler Velocimeter) was set up downstream of the barrage on a gantry to record point velocities. The downstream depth was controlled by a $0.15 \mathrm{~m}$ high weir at $2.8 \mathrm{~m}$ downstream from the barrage. The experimental set up is shown in Fig. 1 (further details in Jeffcoate 2013 and Jeffcoate et al 2013).

Firstly, bulb bodies with inclined stators only were added to the duct centres (Fig. 2). The rectangular $0.015 \mathrm{~m} \times 0.022 \mathrm{~m}$ stators were inclined at $30^{\circ}$ from the stream-wise direction and placed in alignment with the rotor blades. The rounded end of the bulb faced upstream. The support structure was fitted between the upstream and downstream sections of the duct to hold the turbine in position. The bulb and stator geometries were based upon the turbines in the La Rance tidal barrage (De Laleu 2009).

Fig. 3 shows the turbines with rotors added; these were four-bladed, axial-flow, model boat propellers, 0.1016m in diameter (Kort Nozzle Propeller type KNP/4051/4/RH/BR). The rotational speed of the La Rance turbines is 93.75rpm (De Laleu 2009) with a maximum overspeed of 260rpm. Froude scaling dictates that the target scaled speed is 1120rpm. With braking due to friction only the maximum speed obtained by the turbines was 153rpm, with an average rotational velocity of $138 \mathrm{rpm}$, the model Froude scale torque cannot therefore be attained. Nevertheless, the effect of swirl due to rotor rotation on flow and, importantly, bed shear can be qualitatively assessed.

The discharge was set so that the tubes were fully submerged and maximum rotation rate was achieved. The discharge and resulting water depths varied depending on the inflow velocity, the height of the downstream weir and the restriction to the flow within the ducts (due to stators and rotors). The head difference would, ideally, be unchanged but when rotors were added the 
velocity, and thus head difference, was increased to maximise the rotation rate. The flow conditions for each set of experiments - (1) no turbines (Jeffcoate et al 2013), (2) bulb with stators only and (3) bulb with stators and rotors - are shown in Table 1. The different conditions isolated the effect of each part of the turbine, namely the effects of adding a body and adding a rotor. The barrage with bulb body, stators and rotors is comparable to a real barrage. Because there are different inflow conditions for each set of experiments the results were nondimensionalised using the upstream reference velocity.

The water depths were measured at $1 D, 2 D, 5 D, 10 D$ and $20 D$ downstream, where the duct diameter $(D)$ is $0.11 \mathrm{~m}$. The velocity profiles across the tank were recorded at $0.04 \mathrm{~m}$ (close to the bed), $0.075 \mathrm{~m}$ (at duct mid-depth), $0.08 \mathrm{~m}$ (close to $0.075 \mathrm{~m}$ ), $0.12 \mathrm{~m}$ and $0.16 \mathrm{~m}$ from the bed and close to the surface. The position close to the surface varied with downstream depth and with distance from the barrage; at $20 D$ downstream the water depth had decreased. The resulting close-to-surface measurement levels were: experiment (1) at $0.195 \mathrm{~m}$ and $0.185 \mathrm{~m}$ at $20 \mathrm{D}$; experiment (2) at $0.2 \mathrm{~m}$ and $0.195 \mathrm{~m}$ at $20 D$; and experiment (3) at $0.185 \mathrm{~m}$ and $0.175 \mathrm{~m}$ at $20 D$. The velocities at $0.01 \mathrm{~m}$ from the bed were also recorded in experiment (2) and (3) only (the ADV that allows this was not available for experiment (1)). The interval spacing for experiment (1) was $0.04 \mathrm{~m}$ and for experiments (2) and (3) this was refined to $0.01 \mathrm{~m}$. The water depths, velocity vectors, and streamwise velocity profiles were used to compare the influence of swirl on the flow kinematics and bed shear stresses.

\section{RESULTS}

\section{Water-Level Variation}

The experimental water depths downstream of the barrage and at $1 D, 2 D, 3 D, 5 D, 10 D, 15 D$ and $20 D$ from the barrage were recorded on one side (right side looking downstream) of the 
flume and at the centreline in the stator/rotor experiment (Fig. 4). The depth decreased with distance downstream from the barrage due to frictional head loss. The addition of stators increased the rate of depth change, but the rotors caused a slight decrease. The depth change is, therefore, predominantly affected by the restriction within the duct and the addition of swirl. These values are also dependent on the flow rate, which varied slightly between experiments. The stator/rotor results also show a drop in the water depth immediately downstream from the barrage at the flume centreline, due to the formation of high velocity jets that occur at the duct exits, compared to the areas of slower, reversed flow at the flume edges. The water levels across the flume become more uniform with distance downstream.

\section{Velocity Vectors}

The measured experimental velocities from all three experiments were non-dimensionalised using the upstream reference velocity; the velocity vectors are shown close to the free surface (Fig. 5a), at the duct centre plane (Fig. 5b) and close to the bed (Fig. 5c). At the two lower levels, the vectors show that jets form directly downstream from the tube exits when there are no turbines, but when there is a bulb within a duct a wake forms downstream. The vectors in both experiments with swirl exhibit this trend, though the jet velocity appears to be greater when there is rotor swirl. As distance from the barrage increases the jets merge and the velocity magnitude becomes more uniform across the flume in all the experiments.

Close to the free surface, however, the jets are no longer evident. There is marked crossstream flow occurring close to the barrage, particularly when generated by swirl. The stator and stator/rotor experiments also show that the flow reverses close to the barrage, indicating the presence of vertical circulation due to the jets. Asymmetric eddies form on both sides of the flume, leading to reversed flow at the tank sides, throughout the depth. The asymmetry is due to 
113 the Coandă effect causing the jets to incline towards one side of the flume (Reba 1966). The

114 experimental results with no turbines show that the largest eddy extends up to $10 D$ downstream,

115 whereas the experiments with swirl have smaller eddies, extending to less than $5 D$ downstream.

116 When there is no swirl the central jet that forms moves slightly to the left, at all depths, due

117 to the Coandă effect. The movement of the jet is different when swirl is added to the model. The

118 swirl causes the jet to move to the left when close to the bed and at duct centre and move to the

119 right when close to the free surface, due to the clockwise swirl when looking downstream. This

120 swirl can be seen in Fig. 6, which shows the non-dimensionalised velocity vectors in the $1 D, 2 D$

121 and $5 D$ downstream vertical planes with swirl from stators and stators/rotors (Jeffcoate 2013).

122 The swirl was classified using two parameters, the non-dimensionalised circulation, $\Gamma_{N-D}$, and the

123 non-dimensionalised angular momentum flux, $A M F_{N-D}$, in order to compare the swirl

124 characteristics of each barrage configuration. The swirl was measured at $1 \mathrm{~cm}$ from the duct exit,

125 the closest point possible to measure without interfering with the flow. The circulation was

126 measured at the outer limit of the duct using the tangential velocity, $U_{\theta}$, and radius, $r$. This was

127 non-dimensionalised using the upstream reference velocity, $U_{i n}$, and the duct diameter, $D$ :

$$
\Gamma_{N-D}=\frac{1}{U_{i n} D} \int U_{\theta} r \cdot d \theta
$$

The average circulation across the ducts with swirl generated from stators was 86.4. When

130 increases the swirl across the ducts. While the circulation defines rotation the angular momentum

131 flux is a direct consequence of the turbine torque imparted to the fluid; this was calculated using

132 the integral of the tangential velocity, $U_{\theta}$, the radius and streamwise velocity, $U_{x}$. The results

133 were also non-dimensionalised using the upstream reference velocity and duct diameter: 


$$
A M F_{N-D}=\frac{1}{U_{i n}^{2} D^{3}} \int U_{x} U_{\theta} r \cdot d A .
$$

The average $A M F_{N-D}$ across the ducts with stators only was 0.71 . When rotors were added to the model the $A M F_{N-D}$ increased to 1.00 . This shows that not only does the tangential velocity increase with distance across each duct radius but so does the streamwise velocity, as shown also by direct measurement in Fig. 6.

Close to the barrage (at $1 D$ ) the swirl downstream from each duct is pronounced, with flow to the left side of the flume close to the bed and to the right close to the free surface. There is an upwelling present in both the experiments due to the vertical recirculation of the flow. Vertical eddies at the flume sides thus form. As distance from the barrage increases, cross-stream secondary motions occur, creating circulation throughout the entire flume cross-section. This is particularly evident at $5 D$ downstream, with near-zero cross-stream and vertical flow at the flume centreline. Note that depth-averaging these results would cause these flow features at $5 D$ to be cancelled out, so the flow close to the bed would be poorly predicted. This is also apparent at $10 D$ (not shown here), though to a lesser extent, and at $20 D$ there is no cross-stream flow.

The velocity vectors show that similar velocities and flow patterns are present in the results with both stator and stator/rotor swirl, but these differ from the results with no swirl. The limited difference in the stator and stator/rotor results may be due to the lack of loading on the rotor, representation of a power take off system.

The extent of the jet influence, the eddy sizes, the asymmetry and the distance downstream where the results become comparable, can be assessed by evaluating the velocity profiles across the tank width. It should be mentioned that these cross flow effects will be influenced by the flume walls and in a real barrage the turbines will be in a limited section as part of a long barrage; nevertheless, similar qualitative effects will almost certainly occur. 


\section{Vertical variation of velocity}

The variation of streamwise velocity throughout the depth was compared at $0.04 \mathrm{~m}, 0.08 \mathrm{~m}$, $0.12 \mathrm{~m}$ and $0.16 \mathrm{~m}$ from the bed and close to the free surface in each experiment, at $1 D, 2 D, 5 D$, $10 D$ and $20 D$ downstream. These have been non-dimensionalised by the upstream velocity.

At $1 D$ downstream from the barrage (Fig. 7a), jets are clearly apparent at $0.04 \mathrm{~m}$ to $0.12 \mathrm{~m}$ from the bed, but the location of the jets varies with vertical level and experiment. When there is no swirl the jets occur directly downstream of each duct. When bulb bodies are added to the model they cause a different profile to form close to the duct centreline, at $0.08 \mathrm{~m}$ from the bed. This profile is expected due to the blockage in the duct. At the centreline the maximum normalised jet velocity is comparable between all three experiments, at approximately 4.5. This shows that the duct exit velocity is the same regardless of the blockage and swirl in the duct. The jet maxima are also comparable close to the bed, due to the proximity of the bed. The jets are slightly off-centre due to the swirl component towards the left of the tank at this depth. Shallower, at $0.12 \mathrm{~m}$ from the bed, the streamwise velocity is higher with stators/rotors because the swirl causes enhanced mixing of the jet vertically. Closer to the free surface the profiles are again similar, due to the vertical recirculation. The reverse flow at the free surface is more pronounced in the experiments with swirl, because there is greater vertical mixing. It should also be noted that experiments (2) and (3) are quite similar, indicating that the adding a rotor to the duct has a less significant effect on the flow than the drag and swirl imposed by the addition of a bulb body with stators.

The jet velocity is slightly larger for experiment (3), with stators and rotors. The ratio of upstream reference velocity to duct inflow velocity in experiments (1) and (2) is 4.27, whereas in experiment (3) it is 5.26, so the normalised velocity profile is higher in experiment (3). 
As distance downstream increases, to $2 D$, the flow features are sustained, though this is not 180 shown. Further downstream, at 5D (Fig. 7b), the profiles have changed significantly. The profile

181 is more uniform across the width in all cases and there are three main differences between the 182 experiments. Firstly, experiment (1) shows large eddies which do not occur in (2) and (3), for the 183 reason previously discussed. Secondly, there is a large Coandă effect that forms close to the 184 surface in experiment (1) only; this is not seen in the other experiment due to the full flume 185 recirculation seen in the velocity vectors of experiments (2) and (3). Lastly, there appears to be 186 constant velocity across the flume for the swirl experiments. This is also due to the full flume 187 cross-flow; analysis of the streamwise velocities only, or depth-averaging, would result in an

inaccurate assumption that there is no variation in the flow with vertical level and width.

This is also the case at $10 D$ downstream (not shown). At $20 D$ downstream, Fig. 7c shows there is no variation in the streamwise velocity with depth and cross-stream location, and magnitudes in the other directions are negligible, as seen in the velocity vectors. There is little difference between the three experiments. This indicates that at $20 D$ downstream blockage and swirl have no effect on the velocity.

\section{Bed shear stress}

Bed shear determines sediment transport rates and thus scour downstream of the barrage. This is difficult to measure directly, particularly in turbulent flow. It is, however, possible to estimate the bed shear stress from measured, near-bed, velocity profiles assuming the log law. The friction velocity $u_{\tau}$ (and, hence, bed stress $\tau_{b}=\rho u_{\tau}^{2}$ ) is estimated from the velocity at the lowest measurement point by inverting the logarithmic mean-velocity profile for a fully-rough boundary layer: 


$$
U(z)=\frac{u_{\tau}}{\kappa} \ln \left(33 \frac{z}{k_{s}}\right),
$$

with wall roughness $k_{s}=0.001 \mathrm{~m}$ (painted wood) and von Karman constant $\kappa=0.41$. For distance from the bed $z=0.01 \mathrm{~m}$ the corresponding value of $z^{+}$, which denotes distance from the wall normalised using the viscous length-scale $z^{+}=z u_{\tau} / v$, was found to be typically in the range 30-200, consistent with the log-law region (Pope 2000). Fig. 8 shows the estimated bed stresses with no turbines, with stators only and with stators/rotors. Stresses are non-dimensionalised by a reference stress:

$$
\tau_{b}=\frac{1}{2} \rho U_{a v g}^{2} c_{f}
$$

where $U_{a v g}$ is the depth-averaged velocity at $20 D$ and $c_{f}=1.49$ is the skin friction coefficient Jeffcoate et al (2013) deduced from integrating the log-law profile.

The magnification close to the barrage is clear and the contours show that the bed stresses close to the barrage can be up to 3 (no turbines), 9 (stators) and 12 (rotors) times the reference stress. The location of maximum bed shear stress occurs closer to the barrage in experiments (2) and (3) compared to experiment (1), which shows that the inclusion of swirl causes increased flow towards the bed closer to the barrage. The three-dimensional effects are clearly substantial and the rotors can have a significant effect on bed stresses. The magnification in shear due to rotors was obtained with a rotation speed about eight times less than that required for Froude scaling due to friction effects in the rotor bearings and the magnification in bed shear over that due to stators alone can only be indicative.

The magnification of bed shear stress or friction coefficient has been previously found for recirculating wakes behind islands by an order of magnitude (Stansby 2003), indicating that this is a general effect to be expected for wake or jet-like flows. 


\section{CONCLUSIONS}

- Flows downstream from barrages are three-dimensional and highly rotational. The extent of rotation is dependent on the turbine representation, with swirl increasing with the addition of stators and then further with rotors.

- Maxima in the velocity occur at the duct centres with open ducts, but at the duct edges with the inclusion of duct blockage. This causes different jet profiles and thus enhanced jet mixing and wake recovery. The duct blockage also has a greater effect on the depth downstream than the type of swirl generation.

- Circulation changes from duct-localised, at $2 D$, to across the flume, at $5 D$ downstream. Depth-averaging methods would not account for this circulation, thus leading to misleading flow predictions.

- Bed shear stresses are magnified with the addition of swirl, which could significantly change the prediction of sediment motion close to the barrage.

- . Only at $20 D$ downstream does the flow become unaffected by duct blockage and swirl.

\section{ACKNOWLEDGEMENT}

Support from the Doctoral Training Account of School of Mechanical, Aerospace and Civil Engineering at the University of Manchester provided by the EPSRC is gratefully acknowledged.

\section{REFERENCES}

Burrows, R., Walkington, I.A., Yates, N.C., Hedges, T.S., Wolf, J., and Holt, J. (2009)a. “The

Tidal Range Energy Potential of the West Coast of the United Kingdom.” Appl. Ocean Res.

31(4), 229-238.

Xia, J. Falconer, R. A. Lin, B. (2010). "Hydrodynamic impact of a tidal barrage in the Severn Estuary, UK.” Renewable Energy, 35(7), 1455-1468. 
Ahmadian, R., Falconer, R.A., and Lin, B. (2010). "Hydro-environmental modelling of the proposed Severn barrage.” Proc. Inst. Civ. Eng., Energy, 163(3), 107-117. Jeffcoate, P. (2013) "Experimental and computational modelling of 3-D flow and bed shear stresses downstream from a multiple duct tidal barrage”. PhD Thesis, University of Manchester Jeffcoate, P., Stansby, P.K. and Apsley, D.D. (2013). "Flow due to multiple jets downstream of a barrage: Experiments 3D computational fluid dynamics and depth-averaged modelling." $J$. Hyd. Eng. 139(7), 754-762

Stallard, T., Collings, R., Feng, T. and Whelan, J. (2013). "Interactions between turbine wakes: Experimental study of a group of three-bladed rotors." Phil. Trans. of the Royal Soc. A: Mathematical, Physical and Engineering Sciences, 371(1985).

Myers, L.E., Keogh, B. and Bahaj, A.S. (2011). "Experimental investigation of inter-array wake properties in early tidal turbine arrays." OCEANS 2011, 8 .

Luznik, L. Van Benthem, M., Flack, K.A. and Lust E.E. (2013). "Near wake characteristics of a model horizontal axis marine current turbine under steady and unsteady inflow conditions". OCEANS 2013, 1-7.

Harrison, M.E., Batten, W.M.J., Myers, L.E. and Bahja A.S. (2010) “Comparison between CFD simulations and experiments for predicting the far wake of horizontal axis tidal turbines." IET Renewable Power Generation, 4(6), 613-627.

McNaughton, J., Afghan, I., Apsley, D.D., Rolfo, S., Stallard, T. and Stansby, P.K. (2014). “A simple sliding-mesh interface procedure and its application to the CFD simulation of a tidal stream turbine." Int. J. Numerical Methods in Fluids, 74(4), 250-269. Department of Energy (1981). "Tidal Power from the Severn Estuary." DEP Energy Paper, 46, 198. 
267 De Laleu (2009). "L'usine maremotrice de la Rance: 40 ans d'exploitation au service d'une 268 production d'electricite inepuisable sans $\mathrm{CO}_{2} . "$

269 Reba, I. (1966). “Applications of the Coandă Effect.” Sci. Am., 214(6), 84-92.

270 Pope, S.B. (2000). Turbulent Flows. $1^{\text {st }}$ Edition, Cambridge University Press.

271 Stansby, P.K. (2003). “A mixing length model for shallow turbulent wakes.” J. Fluid Mech., 495, $272 \quad 369-384$.

273 
274

\begin{tabular}{lllllll}
\hline Experiment & $\begin{array}{l}\text { Upstream } \\
\text { depth, } \\
h_{1}(\mathrm{~m})\end{array}$ & $\begin{array}{l}\text { Downstream } \\
\text { depth, } \\
h_{2}(\mathrm{~m})\end{array}$ & $\begin{array}{l}\text { Head } \\
\text { difference, } \\
H(\mathrm{~m})\end{array}$ & $\begin{array}{l}\text { Discharge, } \\
Q\left(\mathrm{~m}^{3} / \mathrm{s}\right)\end{array}$ & $\begin{array}{l}\text { Inlet } \\
\text { velocity, } \\
U_{\text {in }}(\mathrm{m} / \mathrm{s})\end{array}$ & $\begin{array}{l}\text { Froude } \\
\text { Number }\end{array}$ \\
\hline (1) No turbine & 0.233 & 0.216 & 0.017 & 0.0291 & 0.1025 & 0.0678 \\
$\begin{array}{l}\text { (2) Stators } \\
\begin{array}{l}\text { (3) Stators and } \\
\text { Rotors }\end{array}\end{array}$ & 0.233 & 0.215 & 0.018 & 0.0222 & 0.0783 & 0.0518 \\
\hline
\end{tabular}

275

Table 1 - Experimental flow conditions

276 


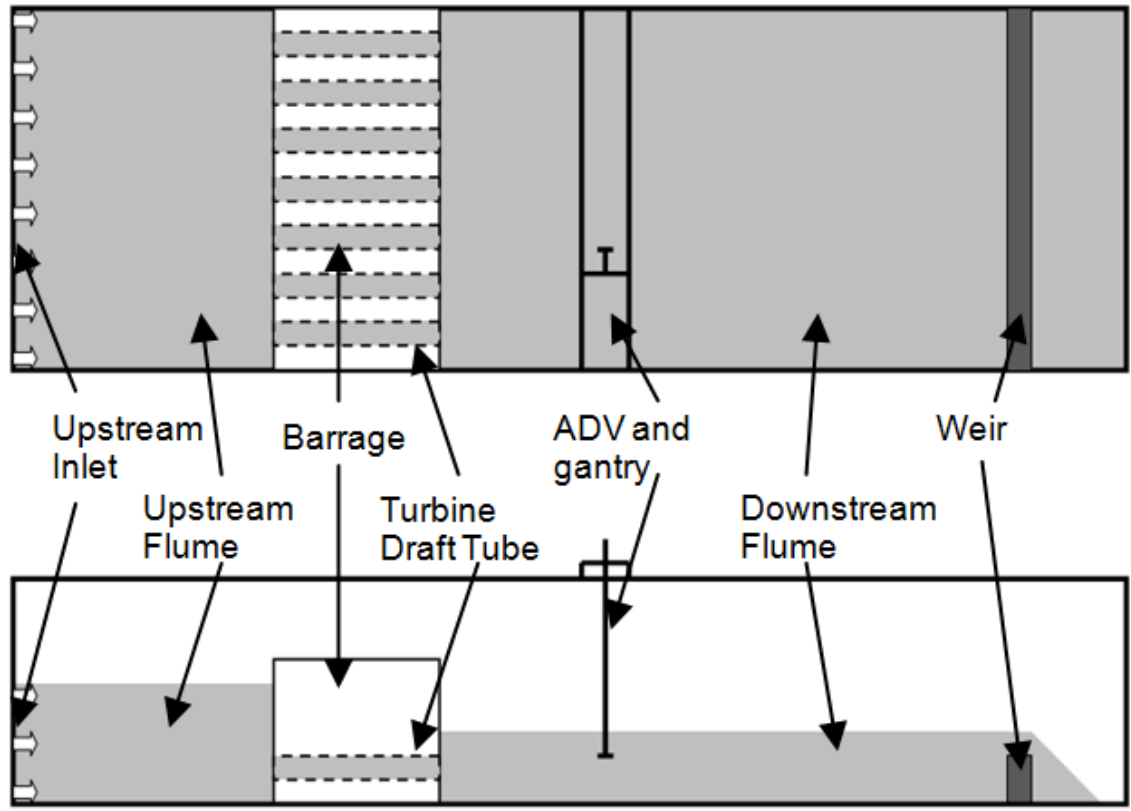

Figure 1 - Barrage schematic
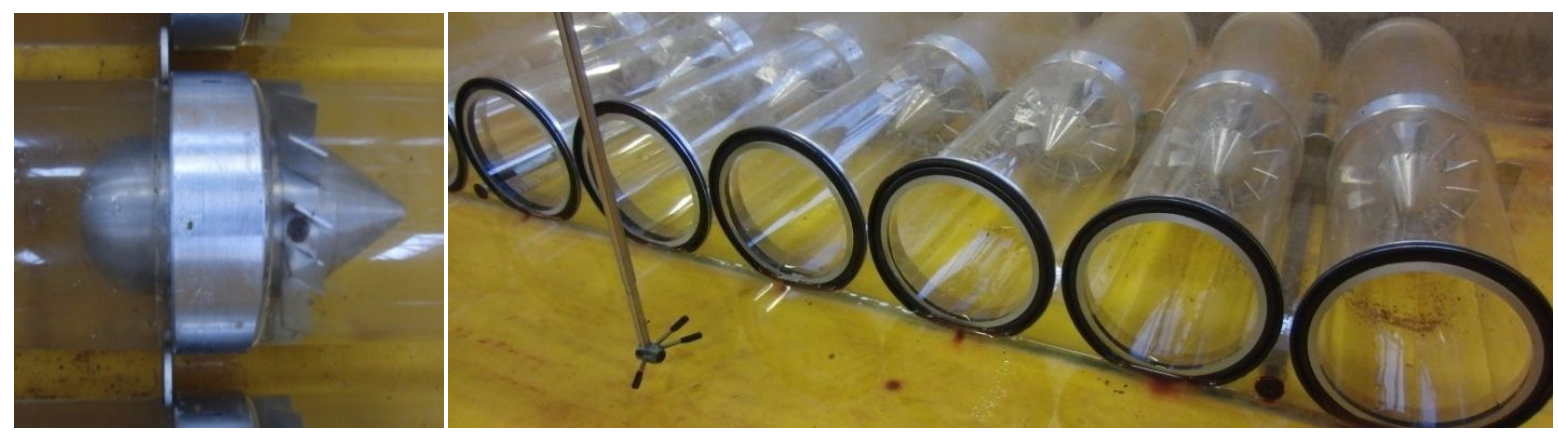

Figure 2 - Turbine representation with bulbs and stators and Vectrino ADV 


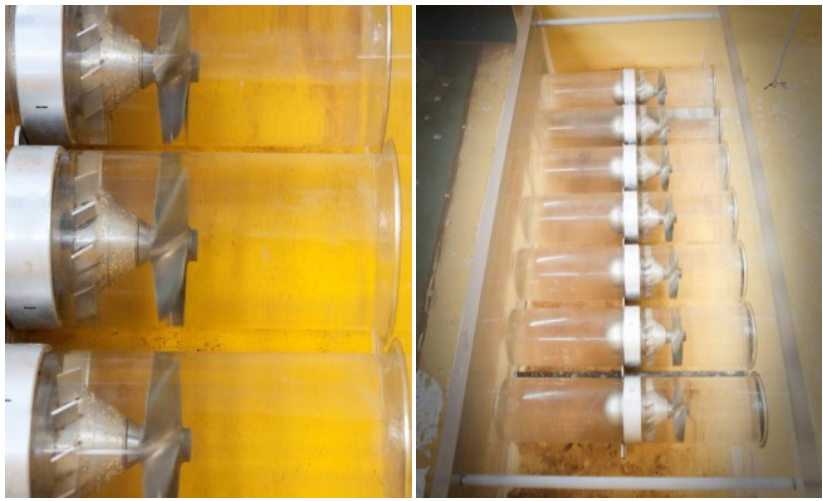

Figure 3 - Turbine representation with bulbs and stators/rotors

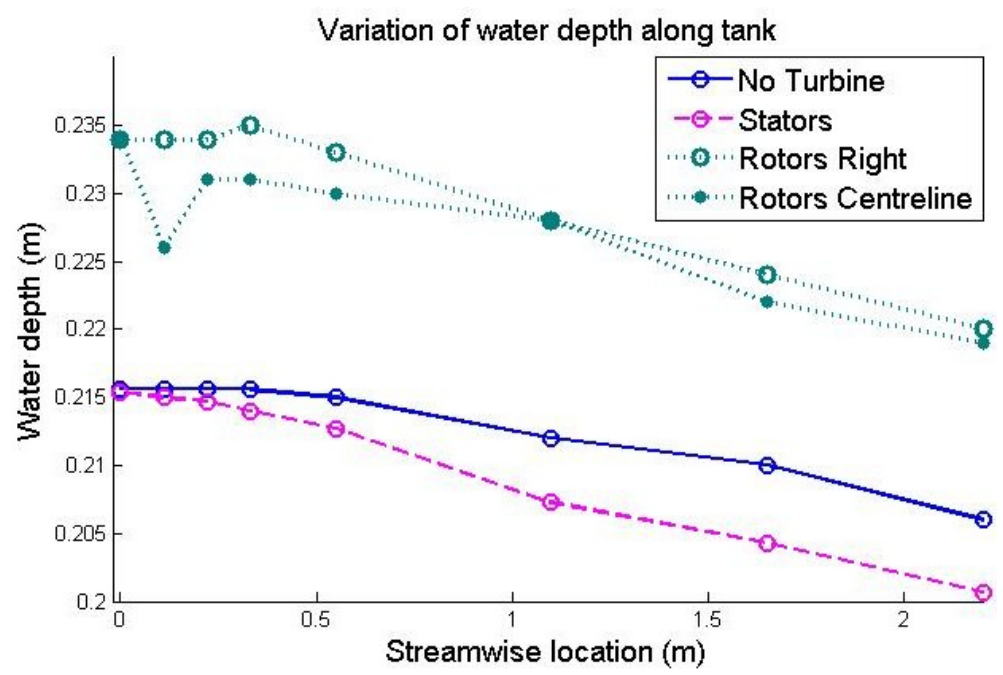




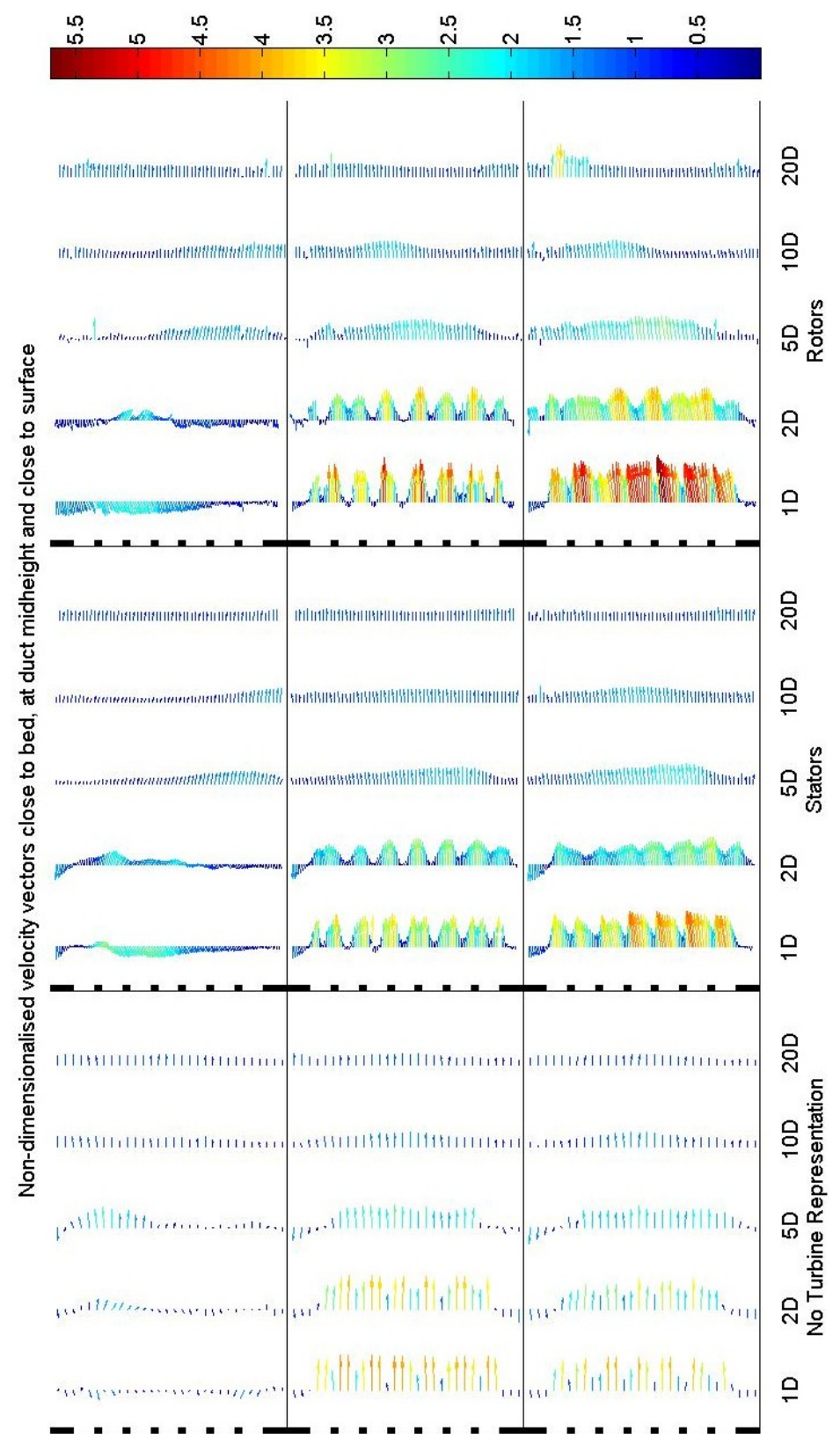

Figure 5 - Non-dimensionalised velocity vectors in X-Y plane, a) Close to bed, b) Duct midheight, c) Close to surface 


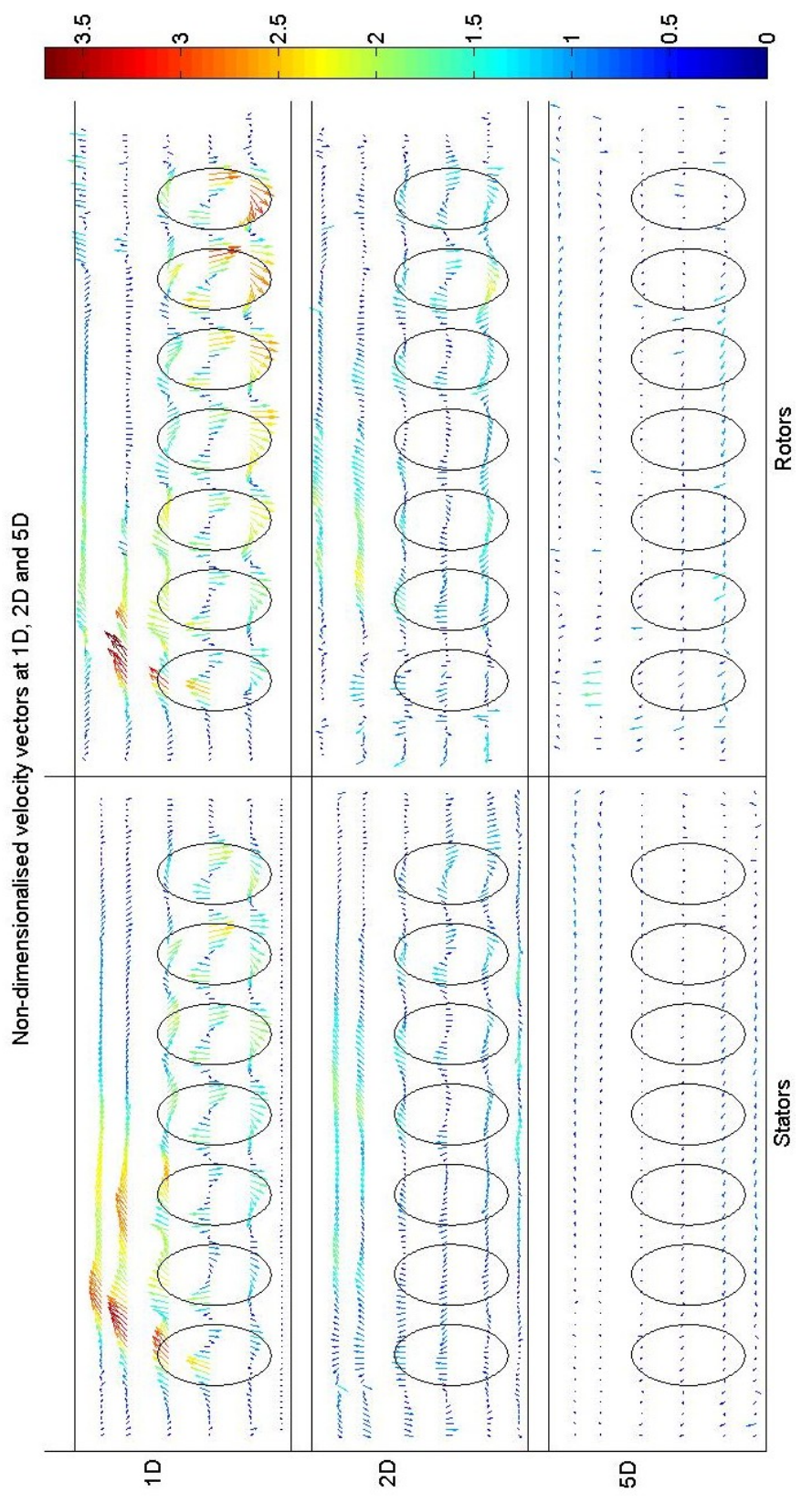

Figure 6 - Non-dimensionalised velocity vectors in Y-Z plane 


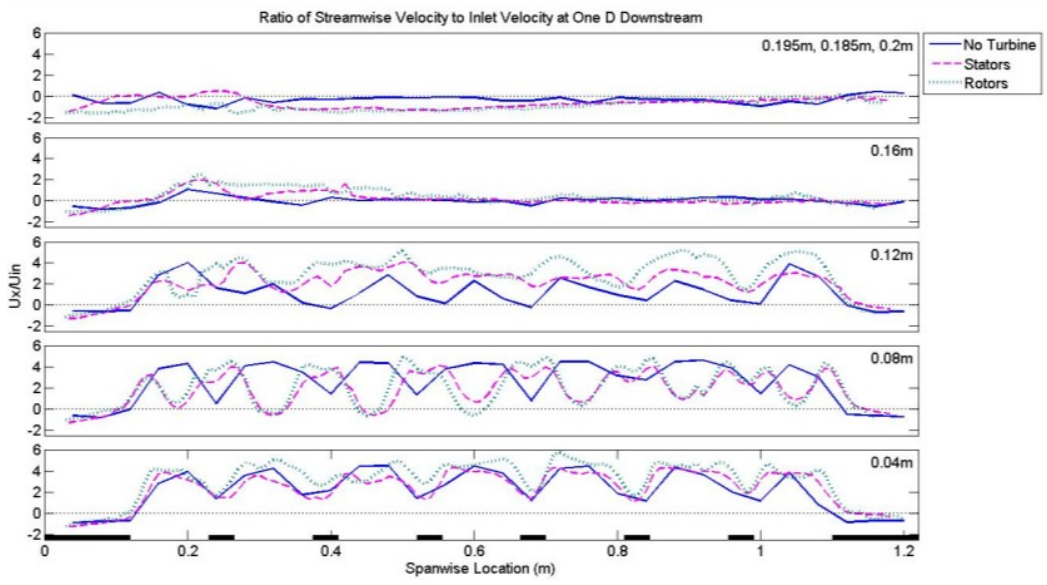

311 Figure 7 (a) - Non-dimensionalised streamwise velocities at one diameter (1D) downstream

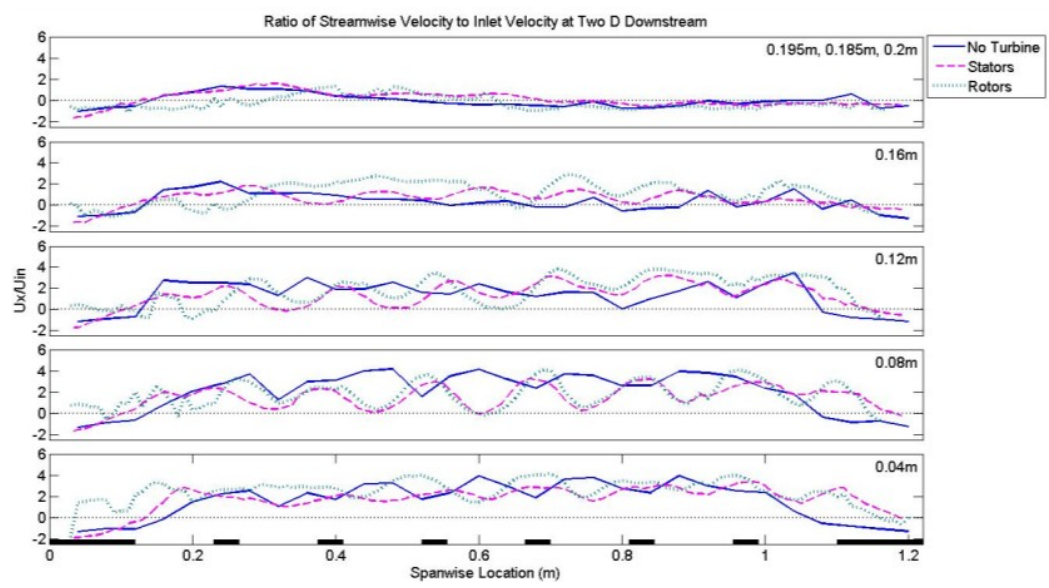

313 Figure 7 (b) - Non-dimensionalised streamwise velocities at two diameters $(2 D)$ downstream

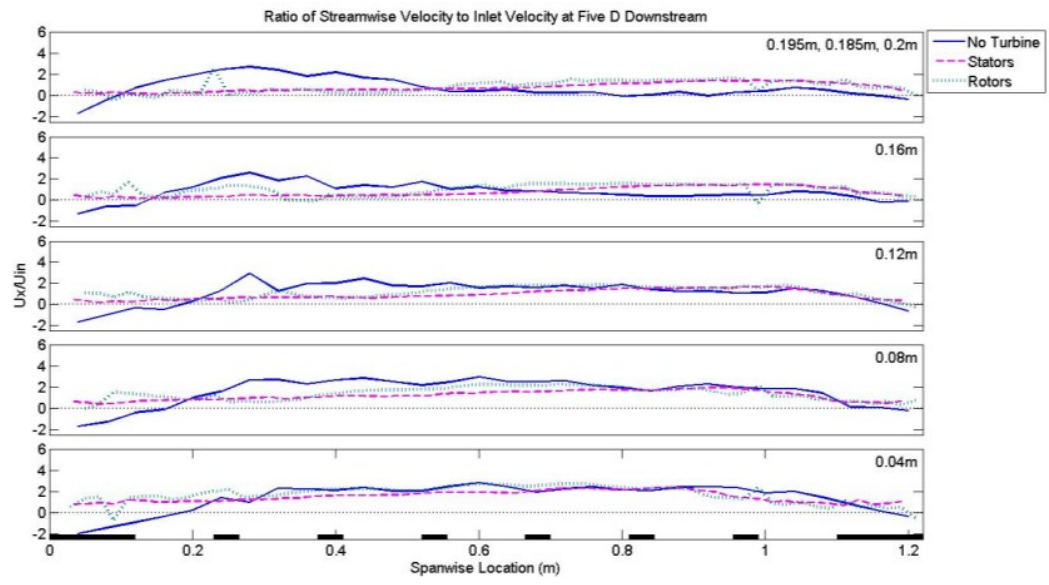

Figure 7 (c) - Non-dimensionalised streamwise velocities at five diameters $(5 D)$ downstream 

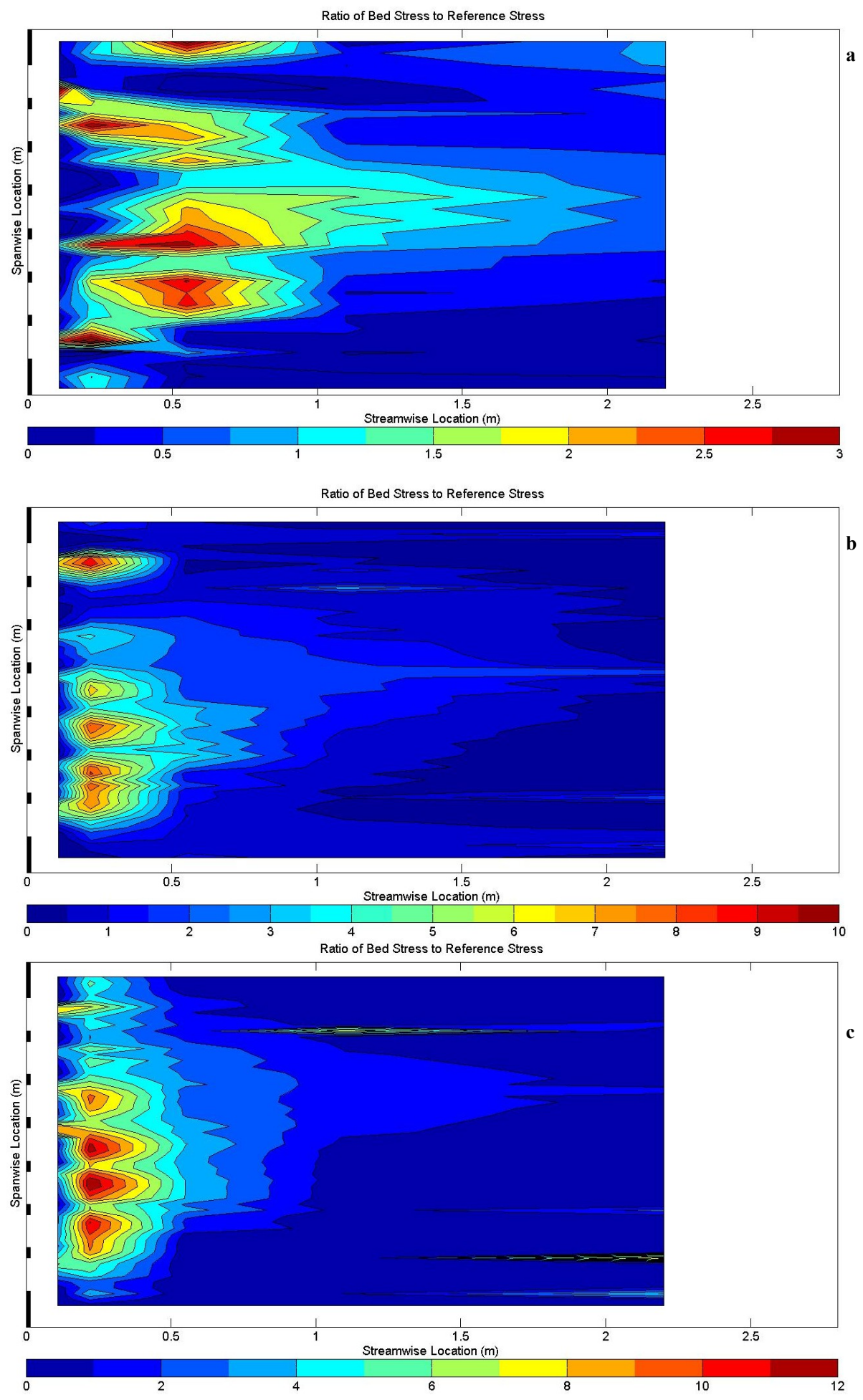

Figure 10 - Normalised experimental bed shear stresses,

a) No turbine representation b) Stators only c) Stators/rotors (NOTE different scales) 